\title{
Effect of polymer structure and additives on silane grafting of polyethylene
}

\author{
J. Morshedian ${ }^{*}$, P. Mohammad Hoseinpour ${ }^{1}, H$. Azizi ${ }^{1}$, R. Parvizzad ${ }^{2}$ \\ ${ }^{1}$ Iran Polymer and Petrochemical Institute (IPPI), P.O. Box: 14965/115, Tehran, Iran \\ ${ }^{2}$ Research and Development Department, Tabriz Petrochemical Company, Tabriz, Iran
}

Received 16 September 2008; accepted in revised form 9 January 2009

\begin{abstract}
Silane method is a preferred method in crosslinking polyethylene to modify its properties. Here, the silane grafting reactions of low density (LDPE), linear low density (LLDPE) and high density polyethylene (HDPE) were compared, all with a fixed amount of silane (vinyltrimethoxysilane) and peroxide (dicumylperoxide). Processing for silane grafting was carried out in an internal mixer, and FTIR spectra were used for comparing the silane grafting efficiencies. The effect of polymer physical form and pre-mixing the components was also determined. Molecular structure parameters were analyzed to investigate their effect on silane grafting efficiency. In case of LDPE and LLDPE, the probable interfering effect of two types of antioxidants on silane grafting reactions was studied. Ethylene propylene diene monomer (EPDM) was added to LDPE to evaluate its effect on silane grafting efficiency. Amongst different grades of polyethylene, LLDPE had a better efficiency in silane grafting. Branchings, PDI, $M_{w}$, and MFI are all determining factors and should be considered in comparing the silane grafting efficiency between different grades of polyethylene. In case of incorporating antioxidant, different results were observed when the polymer under study was different. EPDM as an additive would enhance silane grafting efficiency.
\end{abstract}

Keywords: material testing, branching number, polydispersity index, polyethylene, silane grafting

\section{Introduction}

Un-crosslinked polyethylene has the melting point of $100-130^{\circ} \mathrm{C}$, however, after crosslinking no flow would be noticed even at $150^{\circ} \mathrm{C}[1,2]$, where elastic behaviour prevails. In addition to the advantages associated with crosslinked polyethylene, it is also capable of absorbing high loadings of fillers compared to un-crosslinked polyethylene which becomes brittle on incorporating fillers. By crosslinking polyethylene, some of its important properties (e.g. creep and wear resistance, long term service temperature, impact strength) would also be drastically improved [3-5]; this makes polyethylene a good choice for applications such as hot water pipe, heat shrinkable products, steam resistant food packaging, and foams for thermal insulation.

There are some methods to crosslink polyethylene, among which silane method is a common and beneficial approach to crosslink polyethylene which per se has no functional group or cure site to be crosslinked in a way similar to some other thermoset resins. This method can be done in two ways, either by grafting unsaturated hydrolysable alkoxysilanes onto or copolymerizing them into polyethylene chains $[6,7]$, followed by processing and shaping the polymer into final product and then moisture curing it in the presence of catalyst. In silane crosslinking, siloxane bridges link polyethylene chains together. Recently, it is also possible to 
crosslink the silane-polyethylene copolymer at ambient temperature in the absence of high moisture content, taking the advantage of some special catalysts [8-10]. Easy processing, low cost and capital investments, and favourable properties of processed materials are the advantages of silane method [11]. Further studies on this subject would be found in literature for interested reader [12-16]. Considering the role of antioxidants in preventing or retarding oxidation degradation, it is important to study the proper type of antioxidant in crosslinked polyethylene which has no or the least interference with silane grafting reactions [17-20]. Frequently applied antioxidants for crosslinked polyethylene are mentioned in plastics additives handbook [21], among which the influence of two common types of antioxidants are studied here.

EPDM (ethylene propylene diene monomer) as additive in polyethylene would contribute flexibility to polyethylene, besides improving some properties such as elongation at break and impact resistance [22]. In silane method of crosslinking, due to the reduction of crystallinity in polymer matrix as a result of incorporating EPDM, water diffusion (in moisture curing step) would be enhanced and so does the crosslinking rate. For these reasons, the effect of adding EPDM on grafting efficiency of polyethylene is studied. The result of this study could be generalized to material parameters affecting extent of functionalization or grafting of low molecular weight species to polyethylene by radical reaction in melt mixing.

\section{Experimental}

\subsection{Materials}

\subsubsection{Polymers}

The information of low density polyethylene (LDPE), linear low density polyethylene (LLDPE) and high density polyethylene (HDPE) used in this study can be found in Tables 1 and 2. Ethylene propylene diene monomer (EPDM) with the trade name Vistalon 7500 (supplied by ExxonMobil Chemical Company (USA)), was a terpolymer containing ethylene (55.5 wt\%), propylene and ethylidene norbornene $(5.7 \mathrm{wt} \%)$. All the polymers were received as granules except the EPDM which was in chips form.
Table 1. Suppliers' information for polyethylenes used in this study

\begin{tabular}{|l|l|l|}
\hline \multicolumn{1}{|c|}{ Polyethylene } & \multicolumn{1}{|c|}{ Trade name } & \multicolumn{1}{c|}{ Manufacture } \\
\hline LDPE & LH0075 & $\begin{array}{l}\text { Bandar Imam } \\
\text { Petrochemicals Co. (Iran) }\end{array}$ \\
\hline LLDPE & BPD3052 & $\begin{array}{l}\text { INEOS Group Limited } \\
\text { (United Kingdom) }\end{array}$ \\
\hline HDPE & Ex3 & $\begin{array}{l}\text { Arak Petrochemicals Co. } \\
\text { (Iran) }\end{array}$ \\
\hline
\end{tabular}

Table 2. Properties of polyethylenes used in this study

\begin{tabular}{|l|c|c|c|}
\hline & LDPE & LLDPE & HDPE \\
\hline MFI $\left(190^{\circ} \mathrm{C}, 2.16 \mathrm{~kg}\right)[\mathrm{g} / 10 \mathrm{~min}]$ & 0.70 & 3.50 & 0.40 \\
\hline$M_{n} \cdot 10^{-3}$ & 17.6 & 17.1 & 13.9 \\
\hline$M_{w} \cdot 10^{-4}$ & 12.7 & 6.402 & 13.6 \\
\hline Polydispersity Index (PDI) & 7.234 & 3.736 & 9.770 \\
\hline
\end{tabular}

\subsubsection{Silane}

As the most common silane used in the manufacture of silane crosslinkable polyethylene is vinyltrimethoxysilane [23], here vinyltrimethoxysilane was used as the silane, which was in liquid form and with boiling temperature of $123^{\circ} \mathrm{C}$, and supplied by Evonik Industries, Germany, under the trade name of Dynasilan VTMO.

\subsubsection{Peroxide}

Free radicals are needed to initiate silane grafting by abstracting hydrogen atoms from the macromolecules (said alkylradicals); these free radicals are generated from thermally degradable organic peroxides [24], with the most preferred one being dicumylperoxide. It is also possible for unsaturation on silane to be attacked by peroxide followed by reaction with the polyethylene chain [25]. For the current study, the peroxide was dicumylperoxide with $98 \%$ purity and melting point of $49^{\circ} \mathrm{C}$, supplied by Ashland Inc. (USA), under the trade name of Di-cup 40C.

\subsubsection{Antioxidant}

The antioxidants used in this study are listed in Table 3, all provided by Ciba Specialty Chemicals, Switzerland. 
Table 3. Information of antioxidants used in this study

\begin{tabular}{|l|l|c|}
\hline \multicolumn{1}{|c|}{ Trade name } & \multicolumn{1}{|c|}{ Chemical name } & Designation in this study \\
\hline Irganox $^{\circledR} 1010$ & pentaerythritol tetrakis(3-(3,5-di-tert-butyl-4-hydroxyphenyl)propionate) & AO-1 \\
\hline Irgastab $^{\circledR}$ Cable KV10 & 4,6-bis (octylthiomethyl)-o-cresol & AO-2 \\
\hline
\end{tabular}

\subsubsection{Other material(s)}

Acetone (99.5\% purity) was supplied by Merck Ltd, Germany, and used as received.

\subsection{Equipments}

The Melt Flow Index (MFI) of pure polyethylenes was determined through a model 5MPCA MFI equipment (Ray-Ran Co. England) according to ASTM D1238, under $2.16 \mathrm{~kg}$ load, at $190^{\circ} \mathrm{C}$.

In case of using polyethylenes in powder form the granules were powdered by Pulman Powder Mill, Germany. Pre-mixing was done using a turbomixer (TM-2002 Model) manufactured by Borhan Pooya Chemi Trading Ltd., Iran.

The grafting process was carried out in an internal mixer (Rheomix Haake, SYS 90, NJ, USA) with a Banbury-type rotor. Fourier transform infrared (FTIR) spectroscopy was carried out by FTIR, Bruker IFS 48 on thin films for evaluating the extent of grafting.

Oxidative induction time (OIT) tests were fulfilled for 3.50 milligram of polymer at $200^{\circ} \mathrm{C}$ in Differential Scanning Calorimeter, Stanton Redcraft STA780, according to ASTM D3895.

The molecular weight, polydispersity indices and branchings were determined using Size Exclusion Chromatography (SEC) equipped with a refractive index (RI) detector, an on-line viscometer and a Multi Angle Light Scattering (MALLS) detector. The solvent was 1,2,4-trichlorobenzene (TCB) and the samples were dissolved at $123^{\circ} \mathrm{C}$.

\subsection{Procedure}

\subsubsection{Processing}

All the experiments were carried out using 0.04 weight part peroxide per hundred weight part of polyethylene [phr] and $4 \mathrm{phr}$ silane. A solution of silane and peroxide in predetermined amounts was prepared for each batch, and polyethylene (in granular or powder form) mixed with this solution using turbo-mixer at $1500 \mathrm{rpm}$ for one hour. In case of incorporating antioxidant, an amount of $0.1 \mathrm{phr}$ antioxidant was added to aforementioned solution prior to mixing with polymer in turbo-mixer. Silane grafting of polyethylene was carried out in the melt in a batch operation using internal mixer. The rotor speed, processing time, and the temperature were fixed at $60 \mathrm{rpm}, 15$ minutes, and $190^{\circ} \mathrm{C}$, respectively. For assessing neat polymers (no other reactant) they were processed directly in internal mixer. In incorporating EPDM, it was used as received (in form of chips), and hand-mixed with polyethylene prior to pre-mixing.

\subsubsection{Fourier Transform Infrared (FTIR) sample preparation}

Thin films for spectroscopy analysis were prepared by a hot press at $170^{\circ} \mathrm{C}$, under $30 \mathrm{MPa}$ for $20 \mathrm{sec}-$ onds; samples (or granules) to be pressed were equal weighted and thus the obtained film thicknesses were similar (200 micrometer). After preparation of thin films, each film was immersed in acetone for 3 hours, followed by washing with pure acetone and drying for 1 minute under hot air flow, to get sure about leaching all the remnant (un-reacted) silane out. It should be noted that by hot pressing the films, the un-reacted silane would already evaporated as its boiling point is $123^{\circ} \mathrm{C}$ [26].

\section{Results and discussion}

\subsection{Silane grafting determination}

\subsubsection{Torque monitoring}

Here, the aim is to characterize the influence of molecular structure and additives (EPDM and antioxidants), on the extent of silane grafting in polyethylene. Determination of silane grafting efficiency is important due to its inevitable effect on crosslinking which follows after. The later is not the concern of current study.

During the processing in internal mixer, the first increase in torque observed in Figure 1 is due to 


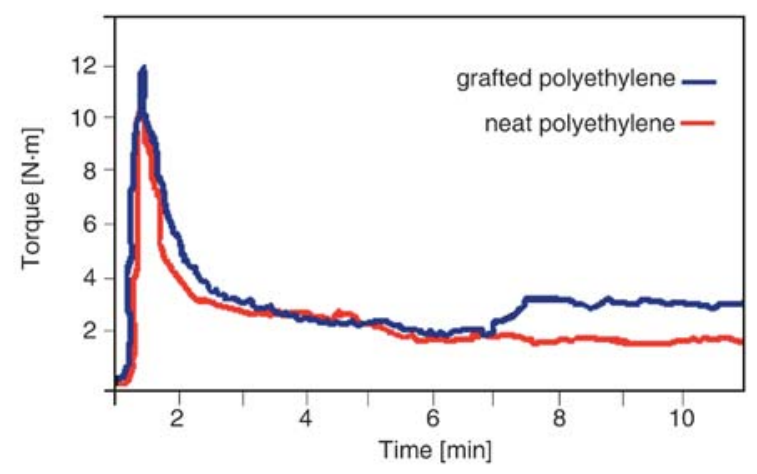

Figure 1. Typical plots of torque vs. time, observed for silane grafted LDPE and the neat one (LDPE without any silane or peroxide)

adding material(s). The torque decreases as the polymer starts plasticating and melting. The following increase in case of silane-containing polyethylene is an indication of starting grafting reactions and is occurred because of the increase in melt viscosity and continues to a plateau. The final torque of silane-grafted polyethylene is higher than that of the neat one (as shown in Figure 1). If the mixing goes further in time, the torque would further increase in result of degradation crosslinking or silane crosslinking in presence of ambient water vapour.

\subsubsection{FTIR characterization}

In studying the FTIR spectra, the transmittance peaks of interest are listed in Table 4. Obviously, the neat polymer has no peak at $1092 \mathrm{~cm}^{-1}$. The $1092 \mathrm{~cm}^{-1}$ is used as an indication of silane grafting extension in samples of this study which typically has the strongest absorbance $[17,27]$ compared to 799 and $1192 \mathrm{~cm}^{-1}$. The peak at $1080 \mathrm{~cm}^{-1}$ is the result of crosslinking, which could occur to some extent even during grafting process. In such cases, the $\mathrm{Si}-\mathrm{OCH}_{3}$ is apt to be masked by strong $\mathrm{Si}-\mathrm{O}-\mathrm{Si}$ absorption [27]. Vinyl and vinylidene groups are considered as the unsaturations in polyethylene and used as one of their microstructure parameters when studying the silane grafting efficiency.

As the film thicknesses (prepared for FTIR study) were almost the same (and if not, hot pressing was repeated to reach the film with desired thickness) and polyethylene shows no transmittance peak at wavenumber of $1092 \mathrm{~cm}^{-1}$, it is possible to consider the height of transmittance peak in this wavenumber as the grafting efficiency and use the corresponding value to compare the silane grafting efficiency in different polyethylenes, although this would be only a realtive comparison and not a quantitative one [26].

\subsection{Effect of pre-mixing and polymer physical form}

Prior to processing in internal mixer, pre-mixing of the silane compound and peroxide with polymers plays an important role in final results, since silane is hardly adsorbed by polyethylene if pre-mixing is not carried out. To demonstrate this dependency, first the LDPE was added to internal mixer (in form of granules) and at the pre-fixed temperature of $115^{\circ} \mathrm{C}$. After melting (observed through the first torque reduction), silane (4 phr) was added to it by using a glass syringe. As the boiling temperature of silane is $123^{\circ} \mathrm{C}$, it is to be added at such a temperature $\left(115^{\circ} \mathrm{C}\right)$. Then, the temperature of internal mixer was set to $190^{\circ} \mathrm{C}$. By reaching this temperature, peroxide $(0.04 \mathrm{phr})$ was added to internal mixer (approximately 18 minutes from the first adding polyethylene to mixer) and the processing was continued till a rise in torque observed (nearly

Table 4. Transmittance FTIR peaks for specified groups

\begin{tabular}{|l|c|c|c|}
\hline \multicolumn{1}{|c|}{ Group } & Structure & Wavenumber [cm-1] & Reference \\
\hline Trimethoxysilane & $\mathrm{Si}-\mathrm{OCH}_{3}$ & $799,1092,1192$ & {$[7,18]$} \\
\hline Siloxane & $\mathrm{Si}-\mathrm{O}-\mathrm{Si}$ & 1080 & {$[18,19]$} \\
\hline Carbonyl & $\mathrm{C}=\mathrm{O}$ & 1720 & {$[28,30,31]$} \\
\hline Vinyl & - & 909,990 & {$[28,30]$} \\
\hline
\end{tabular}


20 minutes after addition of peroxide). It is noteworthy to say that since peroxide would initiate polyethylene crosslinking reactions even at such a low temperature of $120^{\circ} \mathrm{C}$, where silane has still no noticeable activity in such a temperature, in case of adding peroxide together with silane at $115^{\circ} \mathrm{C}$, there would be a strong probability to have undesired crosslinking reactions by consuming peroxide (through formation of $\mathrm{C}-\mathrm{C}$ crosslinks) and hence no further silane grafting at higher temperatures. Thus, by designing the procedures in such a way that the silane was added first (at $115^{\circ} \mathrm{C}$ ), followed by the addition of peroxide at $190^{\circ} \mathrm{C}$, we avoided the undesired possible peroxide initiated crosslinking reactions $(\mathrm{C}-\mathrm{C}$ crosslinks). Besides, by choosing such a low amount of peroxide (0.04 phr) and thus making the ratio of silane to peroxide to be almost 100, and considering that in the silane : peroxide ratios of more than 50 the risk of crosslinking reactions initiated by peroxide reaches almost zero, we avoided the undesired reactions. For confirming this hypothesis, we further performed the gel content tests on some of the final resultant specimens, right after the processing. By immersion of the specimens in boiling xylene, we noticed almost no left polyethylene (as the gel content) after 24 hours. That proved us the reliability of our processing method and reactants ratios.

Once again, the LDPE granules with specified amounts of silane and peroxide was poured in turbo-mixer and mixed for about one hour at $1500 \mathrm{rpm}$ without any heating. As presented in Table 5, in case of the non-premixed sample there is no observed peak at $1092 \mathrm{~cm}^{-1}$ and instead, there is a peak at $1080 \mathrm{~cm}^{-1}$. This peak is a result of forming $\mathrm{Si}-\mathrm{O}-\mathrm{Si}$ bands, i.e. occurrence of silane crosslinking. As it consumes more time to perform the whole process with incorporating silane and peroxide separately into internal mixer (when no pre-mixing was done before), the mixture passed a longer time under processing before reaching the increase in torque. At such a high temperature $\left(190^{\circ} \mathrm{C}\right)$ and with presence of ambient water vapour, crosslinking reactions would commonly

Table 5. Comparison of silane grafting in premixed and non-premixed granular LDPE

\begin{tabular}{|l|c|c|c|}
\hline \multicolumn{2}{|c|}{} & $\begin{array}{c}\text { Non-premixed } \\
\text { granular LDPE }\end{array}$ & $\begin{array}{c}\text { Pre-mixed gran- } \\
\text { ular LDPE }\end{array}$ \\
\hline $\begin{array}{l}\text { Peak height } \\
{[\mathrm{mm}] \text { at }}\end{array}$ & $1092 \mathrm{~cm}^{-1}$ & 0 & 47 \\
\cline { 2 - 4 } & $1080 \mathrm{~cm}^{-1}$ & 21 & 0 \\
\hline
\end{tabular}

occur, and this is not desired. Based upon this observation and since the normalized peak at $1080 \mathrm{~cm}^{-1}$ is still short, indicating the low efficiency in silane grafting prior to crosslinking reactions, all other samples in following experiments went under an hour pre-mixing (in turbo-mixer at $1500 \mathrm{rpm}$ ) prior to their processing.

Now this should be noted that although the procedures were designed to include the pre-mixing step (and not adding silane and peroxide in two steps, as previously mentioned), still both the pre-mixing effect and the silane : peroxide ratio helps avoiding the formation of $\mathrm{C}-\mathrm{C}$ crosslinks, as proved by gel content tests.

To study the importance of polymer physical form (i.e. granular or powder form), LDPE was premixed with specified amount of silane-peroxide solution in powder form. After this pre-mixing and processing, the resultant FTIR spectra have been shown in Figure 2, and the corresponding peak height at $1092 \mathrm{~cm}^{-1}$ are 47 and 63 millimetre for granular LDPE and the powder one, respectively. Thus, it can be inferred that physical form of polymer is of a great importance in increasing the silane grafting extent; in powder form there would be more surface area of polymer to adsorb silane-peroxide solution. To reach this better efficiency, all the polymers were processed at powder form rather

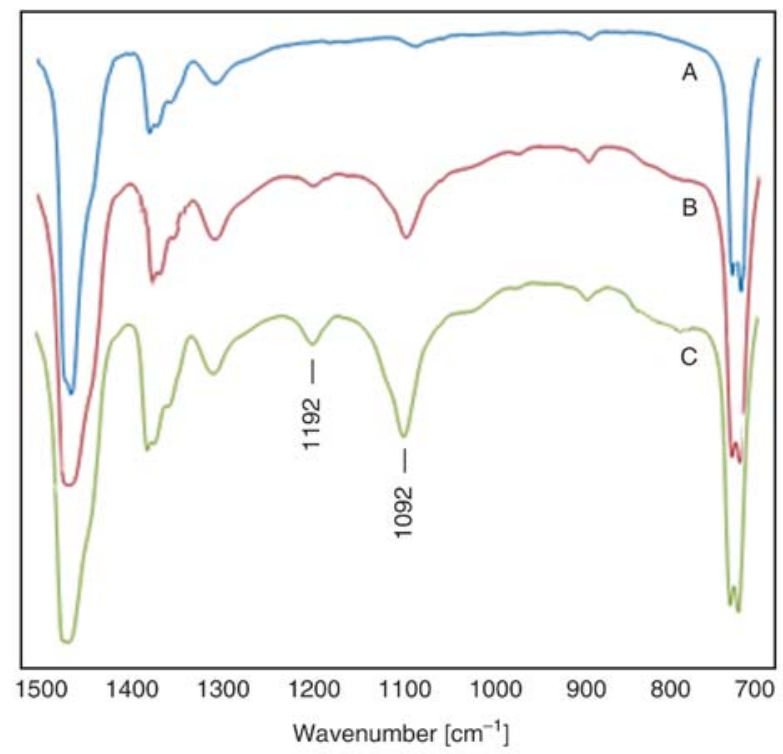

Figure 2. FTIR spectra for LDPE A) neat polymer, B) granular silane grafted, C) powder grafted. Both A) and B) are grafted with 4 and $0.04 \mathrm{phr}$ silane and peroxide, respectively, and the reaction mixture was pre-mixed in turbo-mixer for an hour prior to processing. 
than granular form in all other experiments of the current study.

\subsection{Effect of polymer type}

The extent of silane grafting for similarly grafted LDPE, LLDPE, and HDPE have been determined via their corresponding FTIR spectra and the measured values are presented in Table 6 .

Referring to Table 6, the higher peak height at $1092 \mathrm{~cm}^{-1}$ for LLDPE with respect to that of LDPE and HDPE indicates that LLDPE is more apt to silane grafting reactions compared to LDPE. This is also true for LDPE compared to HDPE. In initiating the silane grafting reaction, peroxide decomposition species would participate in different reactions [2]; they would combine with each other to form unsaturated species; inducing to $\beta$-scissioning in polymer chain and thus leading to chain extension; and finally they would react with the vinyl unsaturation of silane for grafting the molecule onto the polyethylene. Among all the aforementioned reactions, only the last one is desired and the other two would result in molecular structure changes and consequently lead to differences in crosslinking performance [26]. Different types of polyethylene have different tendency and probability for these side reactions and thus different extent of silane grafting would be obtained in fixed amounts of reactants for each type of polyethylene. However, the more efficient grafting in LLDPE rather than LDPE and HDPE, would be also due to existence of tertiary carbons in LLDPE which are

Table 6. Comparison of silane grafting efficiency in LDPE, LLDPE and HDPE

\begin{tabular}{|c|c|c|c|}
\hline Polymer & LDPE & LLDPE & HDPE \\
\hline Peak height $[\mathrm{mm}]$ at $1092 \mathrm{~cm}^{-1}$ & 63 & 70 & 25 \\
\hline
\end{tabular}

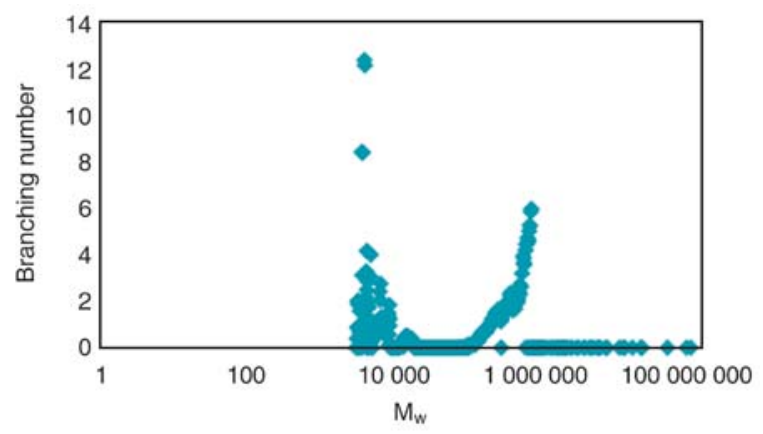

Figure 3. Branching number of LLDPE versus its molecular weight, determined by SEC

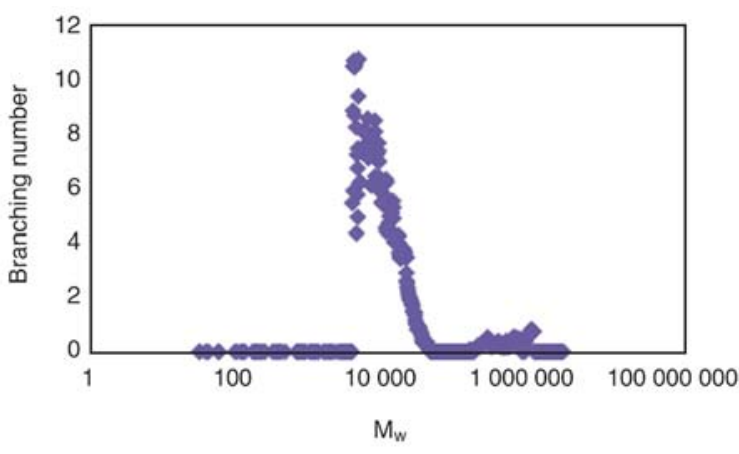

Figure 4. Branching number of LDPE versus its molecular weight, determined by SEC

more apt to react with free radicals initiating grafting reactions [26], since the associated hydrogens are relatively easy to be abstracted during silane grafting reactions. The less tendency to silane grafting in HDPE can be related to the shortage of tertiary carbons: HDPE has ignorable branches. Branching status of LLDPE and LDPE are shown in Figures 3 and 4. As it can be observed, branchings have been spread within all ranges of molecular weight in LLDPE, but in case of LDPE it is only in low molecular weight range, although both have nearly same branching numbers. Thus, the branching distribution (with respect to molecular weight) affect the silane grafting in such a way that wider distribution (bi-modal) (as in case of LLDPE) results in higher grafting, and narrower one contributes to less tendency for silane grafting.

However, there are other factors that would possibly take part in determination of ultimate silane grafting efficiency; it is obvious that the vinyl group in silane is the active site for initiation of grafting on polyethylene in presence of peroxide. Thus, presence of unsaturation in polyethylene itself would positively affect silane grafting initiation. According to Table 4, the corresponding peaks for unsaturation can be detected via FTIR spectra. Only vinyl bonds were investigated here, as they are more active to take part in silane grafting. The vinyl group absorbs at both 909 and $990 \mathrm{~cm}^{-1}$, but only the peak at $909 \mathrm{~cm}^{-1}$ is used here, due to its reported stronger absorption. Considering the magnified FTIR spectra for neat polymers (see Figure 5), LLDPE and HDPE has a peak height 0.055 and 0.052 millimetre, respectively, and the corresponding peak height for LDPE is negligible. Thus, higher relative content of vinyl unsaturation in LLDPE would positively affect its 


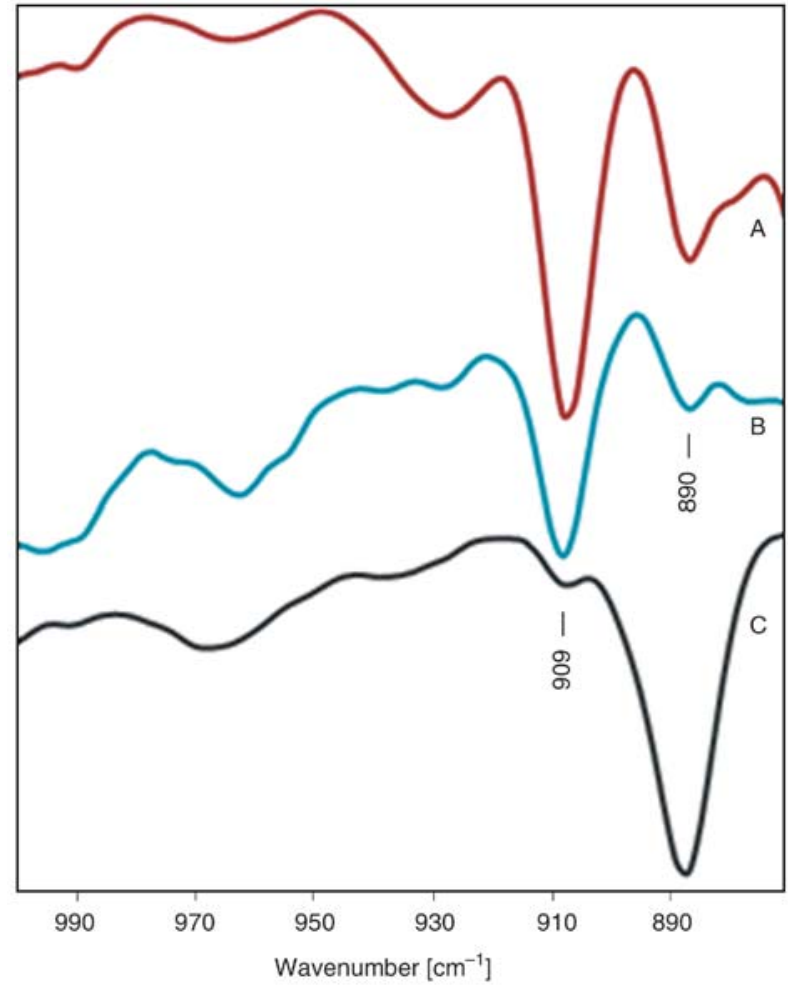

Figure 5. Magnified FTIR spectra for neat polymers, A) LLDPE, B) HDPE, C) LDPE. The transmition range is magnified to show the range of 0.945 to 0.97 , in order to highlight the vinyl unsaturation peaks on polyethylenes.

more efficient performance in silane grafting, while due to the negative cumulative effects of other parameters (discussed above or in the following lines) in HDPE, its vinyl unsaturation would contribute no significant positive effect on its silane grafting.

It should be noted that although a peak at $888 \mathrm{~cm}^{-1}$ can be observed (for LDPE) in Figure 5, it can not be referred to vinylidene unsaturation, as it is always overlapped by absorption at 889 to $903 \mathrm{~cm}^{-1}$ from vibrations of terminal methyl groups on alkyl groups longer than ethyl [32].

Furthermore, as it can be seen from Table 2, these polymers have different polydispersity index values and molecular weights. LLDPE has the lowest PDI, followed by LDPE and HDPE, which means that lower PDI provides more tendency for occurrence of silane grafting. Meanwhile, the higher weight average molecular weight for HDPE and the lower weight average molecular weight for LLDPE would contribute to their level of tendency for grafting reaction; i.e., for LLDPE with low weight average molecular weight, there is more accessibility of polymer backbone for silane and the peroxide decomposition species to start the grafting reactions, while HDPE with higher molecular weight provides less accessibility and LDPE lies between these two. No direct relation can be deduced between number average molecular weights $\left(M_{n}\right)$ and silane grafting efficiency of these polyethylenes.

Moreover, different MFI values should be also taken into account when comparing these types of polyethylene. LLDPE has the highest MFI followed by LDPE and HDPE. This shows that higher MFI would result in more tendency for silane grafting, considering the higher grafting efficiency in LLDPE.

\subsection{Effect of additives}

\subsubsection{Antioxidants}

Antioxidants are normally used to achieve thermooxidative stabilization. During the processing in presence of antioxidants, some part of peroxide could be consumed in a 'non-useful' reaction, which means that this portion has to be compensated for with additional peroxide and if not, there would be lesser silane grafting efficiency. The grafting process limits the choice of antioxidants since many of them are effective radical scavengers and can inhibit the grafting reaction [12]. Here the effect of two types of antioxidants on silane grafting reactions of LDPE is studied. In each case, the antioxidant was added to the silane-peroxide solution and premixed with polyethylene in turbomixer prior to mixing in internal mixer. Table 7 presents the corresponding peak heights. The thermo-oxidative products has the characteristic peaks between 1650 and $1800 \mathrm{~cm}^{-1}$; here the transmittance peak at $1720 \mathrm{~cm}^{-1}$ is considered as the indication of thermo-degradation (designation of

Table.7. Comparison between the silane grafting efficiency and thermal degradation in LDPE for different incorporated antioxidants. All the samples contained $4 \mathrm{phr}$ silane, $0.04 \mathrm{phr}$ peroxide, $0.1 \mathrm{phr}$ antioxidant and premixed in turbo-mixer for one hour, followed by processing in internal mixer for $15 \mathrm{~min}$ at $190^{\circ} \mathrm{C}$.

\begin{tabular}{|c|l|c|c|}
\hline \multicolumn{2}{|c|}{} & \multicolumn{2}{c|}{ Peak height $[\mathbf{m m}]$ at } \\
\cline { 3 - 4 } \multicolumn{2}{|c|}{} & $\mathbf{1 7 2 0} \mathbf{c m}^{-\mathbf{1}}$ & $\mathbf{1 0 9 2} \mathbf{~ m}^{-\mathbf{1}}$ \\
\hline \multirow{3}{*}{ Grafted LDPE with } & AO-1 & 8 & 15 \\
\cline { 2 - 4 } & AO-2 & 4 & 11 \\
\cline { 2 - 4 } & no antioxidant & 14 & 63 \\
\hline
\end{tabular}


$\mathrm{C}=\mathrm{O}$ groups), in which, the neat (un-processed) sample shows no peak while the processed neat one shows a strong peak. Thus the height of this peak is a designation of the extent of degradation (although only comparatively).

Here, it should be noted that except LLDPE (as indicated by its supplier), the other two polyethylenes have some amount of antioxidant but determination and evaluation of this amount and/or type is not of this article's concern, as we aimed to study the effect of antioxidants on silane grafting of as received polyethylenes, that is, the form they are already available in market.

Referring to Table 7, it would be possible to assess the effectiveness of antioxidants: shorter the peak height at $1720 \mathrm{~cm}^{-1}$ and higher the peak height at $1092 \mathrm{~cm}^{-1}$ declares the more effectiveness of antioxidant. In both cases, besides reacting with existing peroxide decomposed species, the antioxidant would also react with the polyethylene alkyl radical which is formed during processing. This may inhibit the grafting reactions. Comparing the peak heights for samples containing antioxidant with the one contains no kind of antioxidant declares this phenomenon.

Incorporation of AO-2 resulted in the least thermal degradation, with respect to AO-1. However, regarding the non-considerable extent of silane grafting, this would be of no advantage to incorporate AO-2 in LDPE in grafting process in aforementioned amounts of silane and peroxide.

The previous experiment was carried out for LLDPE in the same amounts of reactants and conditions. The results obtained from the corresponding FTIR spectra are presented in Table 8.

In case of LLDPE the best antioxidant regarding the least thermal degradation, is AO-2 (as in the case of LDPE), however, in contrary to LDPE, the

Table 8. Comparison between the silane grafting efficiency and thermal degradation in LLDPE for different incorporated antioxidants. All the samples contained $4 \mathrm{phr}$ silane, $0.04 \mathrm{phr}$ peroxide, $0.1 \mathrm{phr}$ antioxidant and premixed in turbo-mixer for one hour, followed by processing in internal mixer for $15 \mathrm{~min}$ at $190^{\circ} \mathrm{C}$.

\begin{tabular}{|c|l|c|c|}
\hline \multicolumn{2}{|c|}{} & \multicolumn{2}{|c|}{ Peak height [mm] at } \\
\cline { 3 - 4 } \multicolumn{2}{|c|}{} & $\mathbf{1 7 2 0} \mathbf{~ c m}^{-\mathbf{1}}$ & $\mathbf{1 0 9 2} \mathbf{~ c m}^{-\mathbf{1}}$ \\
\hline \multirow{3}{*}{ Grafted LLDPE with } & AO-1 & 14 & 31 \\
\cline { 2 - 4 } & AO-2 & 5 & 32 \\
\cline { 2 - 4 } & no antioxidant & 18 & 70 \\
\hline
\end{tabular}

silane grafting efficiency is considerably higher; it should be noted that although the polyethylenes that contain no antioxidant show less difference in grafting efficiency (peak height of $63 \mathrm{~mm}$ in case of LDPE and peak height of $70 \mathrm{~mm}$ in case of LLDPE), the grafting efficiency when adding AO-2, is considerably different for the two polyethylenes (peak height of $11 \mathrm{~mm}$ in case of LDPE and peak height of $32 \mathrm{~mm}$ in case of LLDPE). This shows that while exhibiting frustrating effects, even a same antioxidant would differently affect the silane grafting efficiency, when used in different polymers. Thus, selecting the proper antioxidant for silane grafting of a polyethylene, would not dictate its properness for silane grafting of another polymer.

In a later study it was observed that with employing much higher amounts of silane and peroxide (e.g. up to $6 \mathrm{phr}$ silane and $0.4 \mathrm{phr}$ peroxide) silane grafting would occur in presence of this antioxidant. Based upon OIT tests, maximum $0.1 \mathrm{phr}$ antioxidant would be necessary for preventing the product from degradation (see Figure 6), which imparts 32.92 minute before degradation occurs at $200^{\circ} \mathrm{C}$ (when the amount of antioxidant chosed 0.05 and $0.75 \mathrm{phr}$, the induction time became 19.83 and 23.75 minutes, respectively). Thus, a possible practical method to have a desirable grafting extent besides the least thermal degradation would be to incorporate a part of this predetermined amount within the process and let the left amount incorporated in the catalyst masterbatch (to be used during crosslinking process). This has been done before in case of other additives (such as carbon black) which would interfere with the silane grafting reactions [6]. An alternative choice is making use of higher amounts of peroxide which has disadvan-

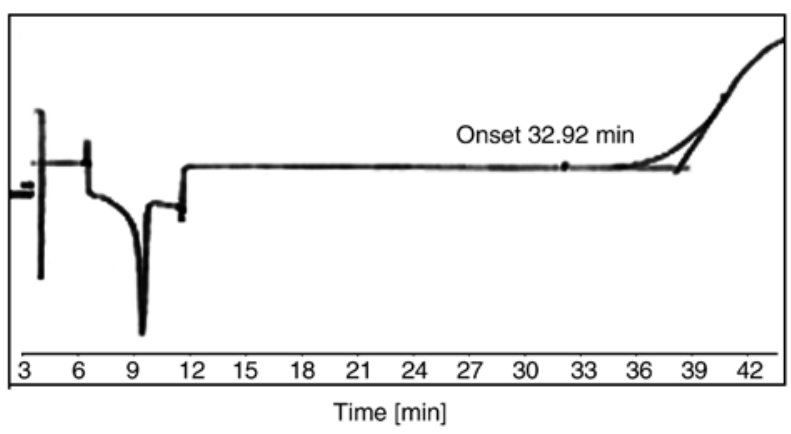

Figure 6. OIT for neat LLDPE containing $0.1 \mathrm{phr}$ of AO-1 (3.5 milligram of sample in aluminium pan under $200^{\circ} \mathrm{C}$ ) 
tage of some scorch occurring during the grafting stage resulting in formation of gelled spots and a rough surface on the product.

\subsubsection{Polymeric additive}

The influence of EPDM as polymeric additive was investigated on silane grafting efficiency of LDPE. The experiment was carried out with a fixed amount of EPDM (2 phr); both polymers were hand mixed in powder form and after pre-mixing with reactants, processed similarly as in aforementioned experiments. According to FTIR analysis, the resultant grafting efficiency (peak height at $1092 \mathrm{~cm}^{-1}$ ) is $78 \mathrm{~mm}$ in case of adding EPDM, which is higher compared to the grafting efficiency of the sample containing no EPDM (in that case the grafting efficiency was 63). This could be due to the unsaturation in diene monomer exists in EPDM, which creates some additional reactive sites for silane grafting to occur (grafting may also occur by the abstraction of secondary hydrogen from a polyethylene sequence of EPDM [33, 34]). A schematic of probable silane grafting on unsaturated bond in EPDM is demonstrated in Figure 7.

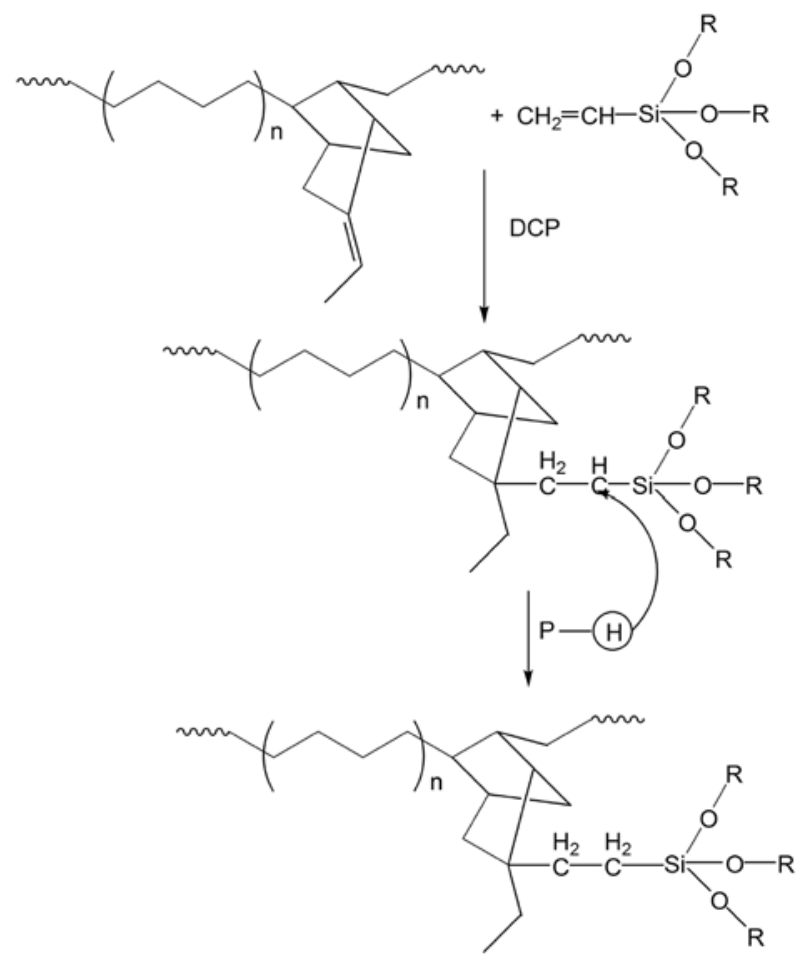

Figure 7. Schematic of silane grafting on EPDM [34]

\section{Conclusions}

In this study it was aimed to characterize the influence of molecular structure, antioxidants type, and EPDM (as additive), on the extent of silane grafting in polyethylene (LDPE, LLDPE and HDPE), in an internal mixer. Grafting reactions can be well monitored through increase in torque and relatively compared by height of FTIR absorption peaks at $1092 \mathrm{~cm}^{-1}$.

It is concluded that, pre-mixing the mixture prior to processing in a turbo-mixer would result in a better efficiency in grafting, and reducing the probability of premature silane crosslinking (as more time would be required in case of not pre-mixing the reactants, which in turn provides the possibility of parallel crosslinking reactions in presence of ambient moisture) during silane grafting reactions. Furthermore, the physical form of polyethylene plays a critical role in this efficiency, as the powder form results in better efficiency with regard to granules. Amongst LDPE, LLDPE and HDPE, LLDPE has the highest grafting efficiency followed by LDPE and finally, HDPE. Higher content of tertiary carbon would be the main reason for higher grafting efficiency in LLDPE, however, other factors such as higher branching number and its broader distribution mode (versus molecular weight), higher unsaturation content in polymer backbone, lower PDI, lower weight average molecular weight, and higher MFI, all positively affect silane grafting efficiency in polyethylene. No direct relation can be deduced between number average molecular weights $\left(M_{n}\right)$ and silane grafting efficiency of the polyethylenes under study.

In case of adding antioxidant in LDPE or LLDPE, each of them frustrates the grafting reactions on polyethylene; however, their relative effect on silane grafting was different. That is, although antioxidants reduce the occurrence of the silane grafting reactions, an antioxidant would have less or more effect on the silane grafting efficiency or thermo-degradation of different types of polyethylene.

Considering that the $0.1 \mathrm{phr}$ antioxidant (used in this study) would be necessary for preventing the product from degradation, a possible practical method to have a desirable grafting extent (in both 
LDPE and LLDPE) besides the least thermal degradation would be the incorporation of a part of this predetermined amount within the process and have the left amount to be mixed in the catalyst masterbatch (to be used during crosslinking process). Another method is increasing the amounts of peroxide, which makes the possibility of some scorch occurring during the grafting stage which in turn results in the formation of gelled spots and a rough surface on the product.

In case of adding EPDM to LDPE, the resultant silane grafting efficiency is higher compared to the grafting efficiency of the sample which contains no EPDM.

\section{References}

[1] Peacock A. J.: Handbook of polyethylene, structures, properties, and applications. Marcel Dekker, New York (2000).

[2] Narkis M., Tzur A., Vaxman A., Fritz H. G.: Some properties of silane-grafted moisture-crosslinked polyethylene. Polymer Engineering and Science, 25, 857862 (1985). DOI: $10.1002 /$ pen.760251311

[3] Zhu Y., Yoon H. G., Suh K. S.: Electrical properties of silane crosslinked polyethylene in comparison with DCP crosslinked polyethylene. IEEE Transactions on Dielectrics and Electrical Insulation, 6, 164-168 (1999). DOI: $10.1109 / 94.765906$

[4] Shieh Y-T., Liu C-M.: Silane grafting reactions of LDPE, HDPE and LLDPE. Journal of Applied Polymer Science, 74, 3404-3411 (1999). DOI: 10.1002/(SICI)1097-4628(19991227)74:14<3404:: AID-APP14>3.0.CO;2-S

[5] Gale G. M.: Silane compounds in hot-water pipe and cable technology. Applied Organometallic Chemistry, 2, 17-31 (1988). DOI: $10.1002 /$ aoc. 590020104

[6] Mehrabzade M., Morshedian J., Barzin J.: Preparation of silane grafting and crosslinking of polyethylene: Studies of the factors affecting the grafting and crosslinking. Iranian Journal of Polymer Science and Technology, 1, 3-10 (1998).

[7] Hjertberg T., Palmlof M., Sultan B. A.: Chemical reactions in crosslinking of copolymers of ethylene and vinyltrimethoxy silane. Journal of Applied Polymer Science, 42, 1185-1192 (1991). DOI: 10.1002/app.1991.070420503

[8] Dammert R., Gustafsson B., Sultan B-Å. K.: Polyethylene compatible sulphonic acids as silane crosslinking catalysts. U.S. Patent 6005055, USA (1999).
[9] Blank W. J., Hessel E. T., Abramshe R. A.: Alkylaryl and arylalkyl monosulfonic acid catalysts for crosslinking polyethylene. U.S. Patent 6441097, USA (2002).

[10] Irestahl E., Lindahl S.: Cross-linking studies of PEVTMS/Visico, effects of $\mathrm{TiO}_{2}$ addition on catalyst performance, kinetics of the cross-linking reaction. Linköping University, Department of Physics, Chemistry and Biology (2008).

[11] Barzin J., Azizi H., Morshedian J.: Preparation of silane-grafted and moisture cross-linked low density polyethylene: Part I: Factors affecting performance of grafting and cross-linking. Polymer- Plastics Technology and Engineering, 45, 979-983 (2006). DOI: $\underline{10.1080 / 03602550600718209}$

[12] Sultan B. A., Palmlof M.: Advances in crosslinking technology. Plastics, Rubber and Composites, Processing and Applications, 21, 65-73 (1994).

[13] Kuan H-C., Kuan J-F., Ma C-C., Huang J-M.: Thermal and mechanical properties of silane-grafted water crosslinked polyethylene. Journal of Applied Polymer Science, 96, 2383-2391 (2005). DOI: 10.1002/app.21694

[14] Azizi H., Barzin J., Morshedian J.: Silane crosslinking of polyethylene: The effects of EVA, ATH and $\mathrm{Sb}_{2} \mathrm{O}_{3}$ on properties of the production in continuous grafting of LDPE. Express Polymer Letters, 1, 378-384 (2007).

DOI: $10.3144 /$ expresspolymlett.2007.53

[15] Venkatraman S., Kleiner L.: Properties of three types of crosslinked polyethylene. Advances in Polymer Technology, 9, 265-270 (1989). DOI: $10.1002 / \mathrm{adv} .1989 .060090308$

[16] Shieh Y-T., Hsiao K-I.: Thermal properties of silanegrafted water-crosslinked polyethylene. Journal of Applied Polymer Science, 70, 1075-1082 (1998). DOI: 10.1002/(SICI)1097-4628(19981107)70:6<1075:: AID-APP4>3.0.CO;2-L

[17] Aizan W., Abdul Rahman W.: Design of silane crosslinkable HDPE compounds for automotive fuel tank application. Project no. 03-02-06-0089, Faculty of Chemical and Natural Resource Engineering, Universiti Teknologi Malaysia (2006). http://eprints.utm.my/2782/1/74125.pdf

[18] Mallegol J., Carlsson D. J., Deschenes L.: A comparison of phenolic antioxidant performance in HDPE at 32-80 ${ }^{\circ} \mathrm{C}$. Polymer Degradation and Stability, 73, 259-267 (2001). DOI: $\underline{10.1016 / \mathrm{S} 0141-3910(01) 00086-6}$

[19] Yamazaki T., Seguchi T.: ESR study on chemical crosslinking reaction mechanisms of polyethylene using a chemical agent- II. The effect of phenolic antioxidants. Journal of Polymer Science Part A: Polymer Chemistry, 35, 2431-2439 (1997).

DOI: 10.1002/(SICI)1099-0518(19970915)35:12<2431:: AID-POLA13>3.0.CO;2-8 
[20] Catalina F., Pienado C., Allen N. S., Corrales T.: Chemiluminescence of polyethylene: The comparative antioxidant effectiveness of phenolic stabilizers in low-density polyethylene. Journal of Polymer Science Part A: Polymer Chemistry, 40, 3312-3326 (2002). DOI: $10.1002 /$ pola.10419

[21] Gachter R., Müller H.: Plastics additives handbook. Hanser Publishers, Munich (1993).

[22] Kumar M. S. C., Alagar M., Prabu A. A.: Studies on dynamic mechanical and mechanical properties of vinyloxyaminosilane grafted ethylene propylene diene terpolymer/linear low density polyethylene (EPDM-gVOS/LLDPE) blends. European Polymer Journal, 39, 805-816 (2003).

DOI: $10.1016 / \mathrm{S} 0014-3057(02) 00285-9$

[23] Shieh Y-T., Tsai T-H.: Silane grafting reactions of low-density polyethylene. Journal of Applied Polymer Science, 69, 255-261 (1998).

DOI: 10.1002/(SICI)1097-4628(19980711)69:2<255:: AID-APP6>3.0.CO;2-M

[24] Ultsch S., Fritz H. G.: Crosslinking of LLDPE and VLDPE via graft-polymerized vinylteimethoxysilane. Plastics and Rubber Processing and Applications, 13, 81-91 (1990).

[25] Shah G. B., Fuzail M., Anwar J.: Aspects of the crosslinking of polyethylene with vinyl silane. Journal of Applied Polymer Science, 92, 3796-3803 (2004). DOI: 10.1002/app.20381

[26] Wong W. K., Varrall D. C.: Role of molecular structure on the silane crosslinking of polyethylene: The importance of resin molecular structure change during silane grafting. Polymer, 35, 5447-5452 (1994). DOI: $10.1016 / \mathrm{S} 0032-3861(05) 80008-4$

[27] Launer P. J.: Infrared analysis of organosilicon compounds: Spectra-structure correlations. in 'Silicone compounds register and review' (eds.: Anderson R., Arkles B. C., Larson G. L.) Petrarch Systems, Bristrol, 47-53 (1987).
[28] Smedberg A., Hjertberg T., Gustafsson B.: Crosslinking reactions in an unsaturated low density polyethylene. Polymer, 38, 4127-4138 (1997).

DOI: 10.1016/S0032-3861(96)00994-9

[29] Mizutani T., Tsukahara T., Ieda M.: The effects of oxidation on the electrical conduction of polyethylene. Journal of Physics D: Applied Physics, 13, 1673-1679 (1980).

DOI: $\underline{10.1088 / 0022-3727 / 13 / 9 / 015}$

[30] Haslam J., Willis H. A., Squirrel D. C. M.: Identification and analysis of plastics. Butterworth, London (1972).

[31] Andersson L. H. U., Hjertberg T.: The effect of different structure parameters on the crosslinking behavior and network performance of LDPE. Polymer, 47, 200-210 (2006). DOI: $10.1016 /$ j.polymer.2005.11.023

[32] ASTM D3124: Standard test method for vinylidene unsaturation in polyethylene by infrared spectrophotometry (1998).

[33] Alagar M., Abdul Majeed S. M., Selvaganapathi A., Gnanasundaram P.: Studies on thermal ageing and morphological characteristics of EPDM-g-VTES/ LLDPE. European Polymer Journal, 42, 336-347 (2006).

DOI: $\underline{10.1016 / j . e u r p o l y m j .2005 .07 .013}$

[34] Alagar M., Abdul Majeed S. M., Nagendiran S.: Preparation and characterization of vinyltriethoxysilane grafted ethylene propylene diene terpolymer/linear low density polyethylene (EPDM-g-VTES/ LLDPE) blends. Polymers for Advanced Technologies, 16, 582-591 (2005).

DOI: $10.1002 /$ pat.626 